\title{
Exergetic Model of Secondary Successions for Plant Communities in Arid Chaco (Argentina)
}

\author{
Marcos Karlin, Rodrigo Galán, Ana Contreras, Ricardo Zapata, \\ Rubén Coirini, and Eduardo Ruiz Posse
}

Facultad de Ciencias Agropecuarias, Universidad Nacional de Córdoba, Avenida Valparaíso s/n, Ciudad Universitaria, C.C. 509, 5000 Córdoba, Argentina

Correspondence should be addressed to Marcos Karlin; mkarlin@agro.unc.edu.ar

Received 24 March 2013; Accepted 19 May 2013

Academic Editors: A. Chistoserdov, H. Ford, and P. M. Vergara

Copyright (c) 2013 Marcos Karlin et al. This is an open access article distributed under the Creative Commons Attribution License, which permits unrestricted use, distribution, and reproduction in any medium, provided the original work is properly cited.

Ecosystems are open systems where energy fluxes produce modifications over plant communities. According to the state and transition model, plant formations are defined by changes in natural conditions and disturbs. Based on these changes, it is possible to define vectors that show the tendencies of the communities towards other states. Within the subregion of Arid Chaco, mature communities of Aspidosperma quebracho blanco represent the quasistable equilibrium communities or "climax," similar to that observed in the Chancaní Natural Reserve (Córdoba, Argentina). Biodiversity values and Lyapunov coefficients were calculated based on plant abundance and cover data. Lyapunov coefficients were calculated as the Euclidean distance of each site with respect to reference condition (community of Aspidosperma quebracho blanco), representing for each state the necessary exergy to reach the reference condition. When Lyapunov coefficients decrease in time, it is expected for the system to drive towards a quasistationary state; otherwise, the equilibrium is unstable and becomes less resilient. The diversity of species has a significant effect over the resistance to perturbations but equivocal for the recovery rate. Lyapunov coefficients may be more precise succession indicators than biodiversity indexes, representing the amount of exergy needed for a vegetation state to reach the reference condition.

\section{Introduction}

Ecosystems are open systems that exchange energy with the surrounding environment, modifying among other components the plant frequencies. Based on these changes it is possible to define vectors that show the tendencies of the succession to reach mature or quasistationary states and their modifications by natural or anthropic disturbances [1]. Concepts of succession are based on the observation and the analysis of the system's states over space and time.

The search for a successional theory that can be empirically verified is still ongoing. From the successional theories of Clements [2], Gleason [3], and Tansley [4], there is no reconciliation between multiple aspects of such theories. The first is based fundamentally on a deterministic mechanism where, starting from an initial vegetation state, succession moves by an autoorganization process through distinguishable phases (communities) reaching a "monoclimax" situation. For Gleason, the main defect of this theory is precisely the change of phases from community to community. This author claims for a succession given by the substitution species by species [5]. Tansley developed similar concepts as those of Clements; nevertheless, he argues about the possibility of reaching multiple "climax" states through its "policlimax" concept.

Westoby et al. [6] developed a new successional model, originally made for rangelands, though suitable for other ecosystems [7-9]. This is based on the description of a group of discreet vegetation "states" and "transitions" among states. The state changes are triggered by natural events such as fire or by anthropic effects. According to these authors, this model is a practical way to organize the information for the management of natural areas, without following theoretical models of environmental dynamics.

Accounting for the type and number of species defining a subsystem (vegetation states), it is possible to determine the abundance and frequency of the present species in each one, defining the amount of accumulated information. A higher 
amount of information in each state can be traduced in free energy available for work; that is, information and energy are intimately related [10].

In a determined vegetation state, higher values of abundance, frequency, and richness should mean higher amounts of energy accumulated in such considered state [11].

If an energy gradient is considered, given by the differences in abundance and frequency among each state, higher energy differences $(\Delta E)$ mean higher differences among states. Lesser differences in energy mean that the successional states are similar (at least from the thermodynamics point of view) [1].

Based on the second and third laws of thermodynamics, it is possible to define entropy as the amount of energy in the system that cannot be used for work. Entropy, originally defined by Boltzmann from the statistical standpoint for the study of ideal gases, can be used to define "the order of the universe," studying the distribution of the gas particles in a closed recipient

$$
S=k \ln \Omega
$$

see [11], where $S$ is entropy, $k$ the Boltzmann constant, and $\Omega$ the possible number of microstates in the system. With a higher number of possibilities, disorder increases.

Within the system, the derivative of entropy $\left(d_{i} S\right)$ can only increase, and therefore

$$
d_{i} S \geq 0
$$

being entropy a spontaneous process, while the entropy exchange between the system and the environment $\left(d_{e} S\right)$ can be positive, negative, or zero, defining the entropy differential $(d S)$ as

$$
d S=d_{i} S+d_{e} S
$$

Therefore, systems' entropy can increase, decrease, or remain constant. This fact can be achieved in dissipative structures [12] depending on the environment conditions.

An analog concept, opposed to entropy, is exergy and information availability $[10,11]$. Energy has different qualities depending on its capacity for being used for work, and this quality can be measured as exergy.

A system's dynamic can be defined in relation to the amount of exergy accumulated. Exergy represents Gibbs potential (free energy) accumulated in the system, and available to be used for work [10].

Analogously to entropy, exergy can be defined as

$$
E x_{i}=T\left(S_{i}^{\mathrm{eq}}-S\right) \quad[10],
$$

where $T$ is temperature, $S$ is entropy, and $S_{i}^{\mathrm{eq}}$ is its value in the $i$ th thermodynamic equilibrium.

Living systems are dependent on outside energy fluxes to maintain their organization and dissipate energy gradients to carry out these self-organizing processes [13]. A forest is a clear example of dissipative structure, evolving naturally towards a minimal entropy state, reducing the disorder produced by the internal entropy with external energy used for photosynthesis processes $[1,14]$.
The ecological exergy is a measure of the distance between the ecosystem in its present state and what it would be if it was at equilibrium with the surrounding abiotic environment, moving along an ecological succession. Exergy is used to build up biomass, which in turn stores Eco-Exergy; Eco-Exergy therefore represents a measure of the structural biomass and the information embedded in the biomass $[10,15]$.

The largest difference between ecosystems and maximum entropic systems is self-organization. Self-organization is the spontaneous emergence of macroscopic order from microscopic disorder, moving towards to a quasistationary equilibrium [16]. The maximum self-organization in an ecosystem is, theoretically, the "climax" state.

Within the subregion of Arid Chaco, mature communities of Aspidosperma quebracho blanco would represent the equilibrium or "climax" vegetation states [17], as seen in sectors of the Chancaní Natural Reserve (ChNR) (Córdoba, Argentina).

Plant formations in this subregion are defined by its natural conditions and by anthropic disturbances produced by the historical extraction of natural resources.

Changes in the ecosystem's physiognomy due to natural resources exploitation, such as logging and grazing, or events such as fires, produce a reduction in the quality of plant biomass and, therefore, a reduction of exergy.

Based on the previous concepts, the posed hypothesis is that within the ecosystem degraded states have less exergy than those states nearer to the quasistationary equilibrium ("climax").

In this paper we seek to identify, understand, and quantify vegetation dynamics in the subregion of the Arid Chaco, as well as to explain the secondary succession dynamics of plant communities from a thermodynamic point of view. For this, we will try to reconcile several aspects of the theories of Clements [2], Gleason [3], and Westoby et al. [6] to gain theoretical support for our thermodynamic model.

\section{Materials and Methods}

This study of ecological successions was conducted at the west of the Sierras de Pocho (Córdoba, Argentina), in the ChNR and surroundings (NW vertex $=31^{\circ} 19^{\prime} 40^{\prime \prime} \mathrm{S}-65^{\circ} 30^{\prime} 07^{\prime \prime} \mathrm{W}$; SE vertex $\left.=31^{\circ} 2436^{\prime \prime}-65^{\circ} 24^{\prime} 3^{\prime \prime}\right)$, representative area for the different vegetation states in the subregion of Arid Chaco. The ChNR is limited by the Prov. Routes No 28 and No 51 at the north and west, respectively, the Chancaní river at the south, and the Sierras de Pocho at the east (Figure 1).

The area is characterized by continental, mesothermal, semiarid climate, with dry winters, high thermal variations, important rainfall oscillations, and high evapotranspiration rates. Rain oscillates annually between 300 and $600 \mathrm{~mm}$. Mean annual temperature is $21^{\circ} \mathrm{C}$, with absolute maximum and minimum of 45 and $-5^{\circ} \mathrm{C}$, respectively. Annual potential evapotranspiration ranges between 1000 and $1200 \mathrm{~mm}$. Winds run from the north (desiccant winds) and from the south (wet winds), conditioned by the north-south direction of the adjacent mountains [18]. 

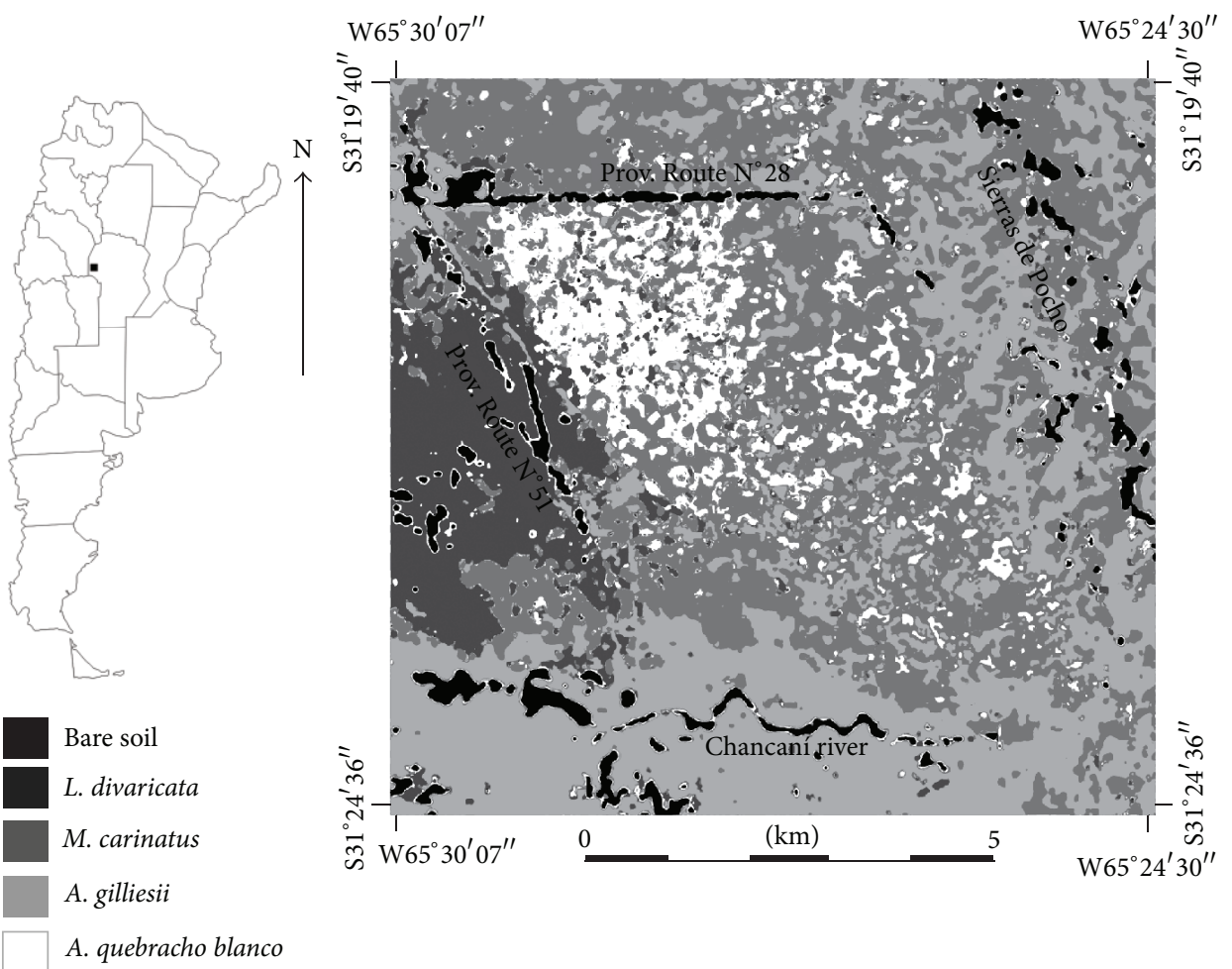

FIgURE 1: Classified image of the study area.

To evaluate the state of secondary successions of this ecosystem, plant dominance and abundance was determined through floristic surveys in sectors of the ChNR and surroundings, previously selected through satellite images, identifying five states and five transitions, according to Westoby et al. [6].

Several homogeneous zones were identified preliminary in the study area through remote sensing techniques, using as cartographic base the chart No 3166-29-1 "Chancaní" of the National Geographic Institute, on a scale 1:50.000. Orbital Landsat 7 ETM+ path/row 230082 images from February 9th 2001 were used. Through visual analysis techniques over false standard color composition (RGB 543) of the image from January 30, 2003, and supported with the Normalized Vegetation Index (NVI), a first approximation of the states and transitions was obtained. With these materials several training sectors were chosen for supervised classification. Each site was geopositioned with GPS and photographed for visual registration. Classification polygons were created and a preclassification was made in order to calculate the statistics and probabilities a priori for the sorter of maximal similarity. Then, a classification with the six bands of the satellite was made obtaining an image of five classes. In order to enhance the visual quality of this product, a modal filter was made with a mobile window of 5 per 5 pixels, being the minimum map unit of 150 per $150 \mathrm{~m}$.

Through basic cartography and field surveys, the zones were preliminary identified and classified, defining vegetation states and transitions.
Based on field surveys, 55 species were identified. Preliminary observations suggest that the dominant vegetation is correlated with the physiognomy of each state; for this reason a Random Stratified Sampling method [19] was applied.

Twenty-two floristic surveys were made in an area of $1 / 4$ ha each. Plant surveys were based on the Phytosociological Method of Braun-Blanquet $[19,20]$. The number of plant surveys made depended on the variability in the number of previously founded species. In the selected sites, dominanceabundance values were estimated.

The dominance-abundance values were transformed into cover values expressed in percentage based on the middle point of each value in the abundance-dominance scale [21] as follows:

+: very rare or rare individuals with negligible cover,

1: abundant individuals, but with negligible cover,

2: individuals in any number, but covering up to $1 / 4$ of the surface area,

3: individuals in any number, with cover ranging from $1 / 4$ to $1 / 2$ of the surface area,

4: individuals in any number, with cover ranging from $1 / 2$ to $3 / 4$ of the surface area,

5: individuals in any number, with superior cover of $3 / 4$ of the surface area.

The values for each species were smoothed through locally weighted regressions (LOWESS algorithm, with a smoothing probability of 0.5 ) [22]. 
Based on this scale, the Shannon-Weaver Biodiversity Index $(H)$ was calculated [21] for each site as

$$
H=-\sum_{i=1}^{n} p_{i} \ln p_{i}
$$

where $p_{i}=N_{i} / \sum_{i=1}^{n} N_{i}, n$ is the number of species in each community, and $N_{i}$ is the size of the population, defined by its relative frequency according to Wikum and Shanholtzer [21].

With the dominance-abundance values of the four dominant identified communities (Aspidosperma quebracho blanco, Acacia gilliesii, Mimozyganthus carinatus, and Larrea divaricata), a discriminant analysis was made to identify classification errors of the surveyed sites. Confidence ellipses were graphed $(P=0.95)$ and finally a definitive classification of the vegetation states was obtained.

In order to quantify the successional series, Lyapunov coefficients $(L)$ values of each state and transition condition were used. Lyapunov coefficients, defined as the property of the behavior of the system in the surrounding of the equilibrium [23], were calculated as the Euclidean distance of each site in relation to the theoretical reference condition ("climax" community of A. quebracho blanco), measured through the sum of relative frequencies of each species, analogously to what was referred in (4). The distance between the quasistable equilibrium state (or the relative frequency expected for the $i$ th species corresponding to the reference condition, $N_{i}^{*}$ ) and the current state (size and current composition of the $i$ th population, $N_{i}$ ) was considered as a measure of the state's disturbance [23] relative to the reference state. Reference values for each species in the community of $A$. quebracho blanco, are referred to as $N_{i}^{*}$ in the Lyapunov coefficients [10]

$$
L=\left[\sqrt{\sum_{i=1}^{n}\left(N_{i}-N_{i}^{*}\right)^{2}}\right]^{2}, \quad i=1, \ldots, n,
$$

where $N_{i}$ is the current situation of the $i$ th species in each site.

$H$ and $L$ values were averaged, standard deviations were determined, and an ANOVA test $(P<0.05$, LSD Fisher $)$ was made for each site in order to determine significant differences.

Lyapunov coefficients were graphed correlated with the dominance-abundance values of the four dominant species, in order to quantify the succession thermodynamically.

\section{Results}

In Figure 1 the spatial location of the different vegetation states can be observed.

Bare Soil. Areas with an incipient cover of ruderal plants. It is represented by the adjacent routes, the Chancaní river, areas of rocky outcrop, and a landing strip at the NW of the Reserve. These areas were not considered for the analysis in the present paper.

Communities of L. divaricata (Lar div). Highly degraded areas by overgrazing, clearcutting, and fire, with total elimination

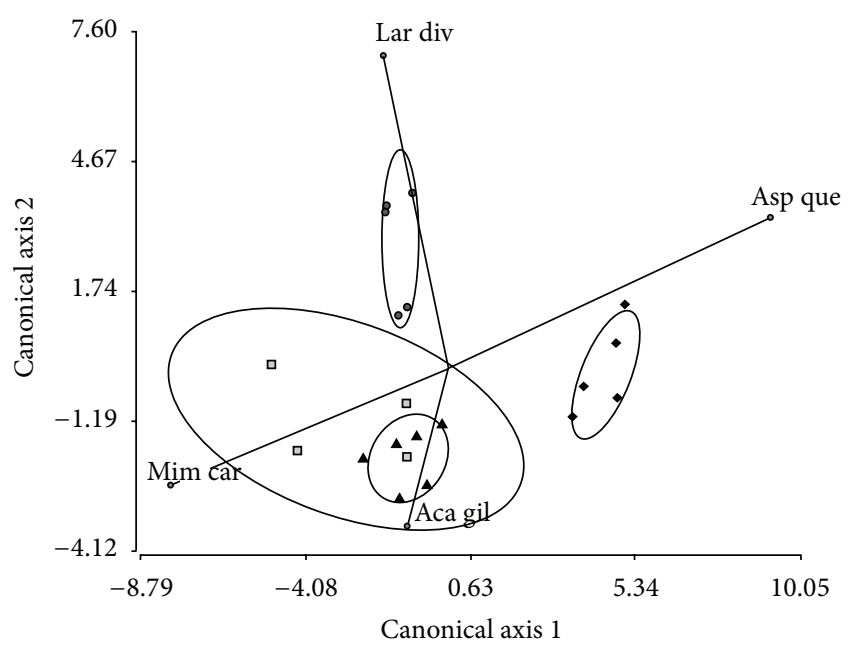

FIGURE 2: Discriminant analysis of the 22 surveyed sites with confidence ellipses $(P=0.95)$. Diamonds: communities of $A$. quebracho blanco ( $n=6$; in the image two sites overlap); triangles: communities of A. gilliesii $(n=6)$; squares: communities of $M$. carinatus $(n=4)$; circles: communities of L. divaricata $(n=6$; in the image two sites overlap). Asp que: A. quebracho blanco; Aca gil: A. gilliesii; Mim car: M. carinatus; Lar div: L. divaricata.

of tree species. It covers the western part of the study area; it includes the NW area of the ChNR, destined for agriculture in the mid twentieth century.

Communities of M. carinatus (Mim car). Areas where wood was indiscriminately extracted before the Reserve declaration. Besides M. carinatus, some herbaceous species such as Abutilon pauciflorum are also important. It covers the southwestern and northern areas of the study area.

Communities of A. gilliesii (Aca gil). Slightly degraded areas by wood extraction, though with lesser intensity than the communities of $M$. carinatus. It covers the margins of the Chancaní river, the Sierras de Pocho hillsides at the east, mixed with mountain vegetation. They also form mixed woodlands with $A$. quebracho blanco in the center of the Reserve.

Communities of A. quebracho blanco (Asp que). These areas are considered as the "climax" state, where anthropic disturbances are not important. These communities are codominated by Cordobia argentea, a herbaceous species. They cover a northwestern core in the Reserve and form mixed woodlands with M. carinatus and A. gilliesii in the center of the Reserve.

In Figure 2, vegetation states clusters can be seen limited by confidence ellipses. The closest point (diamond) to the "Asp que" axis corresponds to the reference state. The communities of A. gilliesii set inside the confidence ellipse of the communities of M. carinatus.

According to the observed in Figures 1 and 2 and to the described disturbs, it is possible to define the transitions. 
Overlapping states represent transitions such as $A$. quebracho blanco-L. divaricata, A. quebracho blanco-A. gilliesii, A. quebracho blanco-M. carinatus, $M$. carinatus-L. divaricata, $A$. gilliesii-M. carinatus.

There are three main vegetation gradients identified, from the "climax" core to the west, south, and east of the ChNR. The first presents more abrupt changes due to the change in the land use for agriculture, representing the A. quebracho blanco- $L$. divaricata transition. To the south, the gradient $A$. quebracho blanco-A. gilliesii-M. carinatus is more gradual due to the wood selective extraction with higher intensity at the southern limit of the ChNR. To the east, the gradient $A$. quebracho blanco-A. gilliesii is influenced by the Sierras de Pocho acting as an important source of biodiversity in these environments.

According to plant surveys made on representative sites, a modal synthetic phytosociological table was made for the study area, obtaining the mean values for $H$ and $L$ with their standard deviations (Table 1).

No significant differences were observed (ANOVA $P<$ 0.05; LSD Fisher) for biodiversity indexes $(H)$ but for Lyapunov coefficients $(L)$. Despite the lack of significant differences for $H$, the highest values correspond to the communities of $M$. carinatus and $A$. gilliesii, while $L$ values decrease significantly from the communities of $L$. divaricata to communities of $A$. quebracho blanco.

Due to the fact that the dynamics analysis was made in a synchronic way, it is not possible to determine the temporal series between states and transitions, and therefore the analyzed parcels are interpreted as chronosequences [5], quantified through $L$ values. These always decrease as the successional series moves towards a reference state (community of $A$. quebracho blanco). It means an increasing in the accumulated exergy along the series.

Higher values of dominance-abundance of those species which are not present in the reference site promote a higher distance in the succession, and therefore Lyapunov coefficients are equivalent to an entropy measure of the system; a higher $L$ value means a lesser amount of exergy accumulated in the community, and it also means that the subsystem needs a higher amount of exergy to reach the quasistable equilibrium (i.e., "climax").

Assuming the occurrence of a secondary succession defined by the exergy values needed to reach a reference state, in Figure 3 the gradients for each one of the dominant plant populations correlating with $L$ can be seen. The communities of $L$. divaricata would constitute the first step in the successional series; this species appears after an important disturbance increasing its participation until it covers the soil completely. As the other dominant populations begin to increase their frequencies, L. divaricata reduces its frequency reaching constant values near $L=0.25$. $L$. divaricata widely dominates degraded areas, although its frequency reduces to a $25 \%$ of the total plant cover with the appearance of $M$. carinatus as dominant species. $M$. carinatus progressively increases its abundance-dominance until it conforms its own community, with maximal frequencies around $L=0.35$. A. gilliesii follows in the series, displacing M. carinatus, reaching its maximal participation with $L=0.28$ and slightly

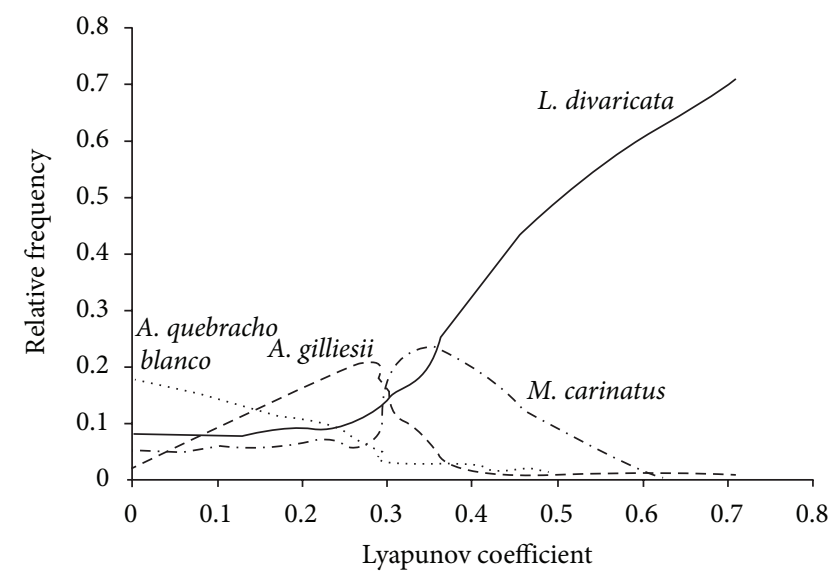

Figure 3: Correlation between Lyapunov coefficients and the relative frequencies of the dominant populations. Asp que: A. quebracho blanco; Aca gil: A. gilliesii; Lar div: L. divaricata; Mim car: $M$. carinatus.

decreasing afterwards while denser populations of $A$. quebracho blanco appear. However, A. gilliesii do not disappear completely within the communities of A. quebracho blanco.

In Figure 3, a transition state between the communities of $M$. carinatus and $A$. gilliesii can be seen near $L=0.30$, where these species mutually exclude.

\section{Discussion}

The different vegetation states that can be currently seen in the ChNR, and by extension in most areas of the Arid Chaco subregion, are mainly defined by the intensity of disturbance over the ecosystem. The elimination of the woody biomass has led to the formation of communities of L. divaricata, $M$. carinatus, and A. gilliesii, competing with herbaceous forage species and affecting natural regeneration of forestry species, forming environments of low productivity.

Figure 2 shows overlapping of communities of $M$. carinatus and $A$. gilliesii because such transitional states are represented by some sites that present similar frequencies of both species.

Analyzing Figure 3, an apparently mature state of the system can be represented by the communities of $A$. quebracho blanco. This state would constitute the "climax" core of the system and is representative of great part of the Arid Chaco [1, $17,24,25]$ defined by the dominated climatic conditions and especially by the characteristics of the azonal soils represented by Typic Torriorthents. The fact that this kind of vegetation state repeats over several points in the subregion suggests an evolution in the successional dynamics towards this "climax" state, in some way deterministic as expressed by Clements in 1916 [2], predicting some aspects of the ecosystem.

Knowing the land use history of the ChNR (see vegetation states in Results section), the study area has suffered two great disturbances of increasing intensity, the first from the climax core towards the south (Chancaní river) by effect of selective logging, and the second by overgrazing, intensive logging, and fire episodes towards the west. The degradation 
TABLE 1: Modal synthetic phytosociological table of the study area by state.

\begin{tabular}{|c|c|c|c|c|}
\hline State & $\begin{array}{l}\text { Community of } \\
\text { L. divaricata } \\
\end{array}$ & $\begin{array}{l}\text { Community of } \\
\text { M. carinatus } \\
\end{array}$ & $\begin{array}{c}\text { Community of } \\
\text { A. gilliesii } \\
\end{array}$ & $\begin{array}{c}\text { Community of } \\
\text { A. quebracho blanco }\end{array}$ \\
\hline Altitude (masl) & 343 & 402 & 366 & 339 \\
\hline \multirow{2}{*}{ Geographic coordinates } & $\mathrm{S} 31^{\circ} 22^{\prime} 07.7^{\prime \prime}$ & $\mathrm{S} 31^{\circ} 23^{\prime} 31.9^{\prime \prime}$ & $\mathrm{S} 31^{\circ} 23^{\prime} 46.4^{\prime \prime}$ & $\mathrm{S} 31^{\circ} 22^{\prime} 07.7^{\prime \prime}$ \\
\hline & $\mathrm{W} 65^{\circ} 28^{\prime} 59.3^{\prime \prime}$ & $\mathrm{W} 65^{\circ} 25^{\prime} 59.6^{\prime \prime}$ & $\mathrm{W} 65^{\circ} 28^{\prime} 18.4^{\prime \prime}$ & $\mathrm{W} 65^{\circ} 28^{\prime} 59.2^{\prime \prime}$ \\
\hline$H(\mu \pm \sigma)^{*}$ & $1.70 \pm 0.37^{\mathrm{a}}$ & $1.98 \pm 0.27^{\mathrm{a}}$ & $1.95 \pm 0.17^{\mathrm{a}}$ & $1.68 \pm 0.24^{\mathrm{a}}$ \\
\hline$L(\mu \pm \sigma)^{*}$ & $0.55 \pm 0.11^{\mathrm{a}}$ & $0.36 \pm 0.03^{b}$ & $0.29 \pm 0.02^{\mathrm{b}}$ & $0.11 \pm 0.09^{c}$ \\
\hline Chloris ciliata Sw. & 1 & & & \\
\hline Sporobolus pyramidatus (Lam.) Hitchc. & + & & & \\
\hline Digitaria californica (Benth.) Henrard & 1 & 2 & & \\
\hline Abutilon pauciflorum A. St.-Hil. & & 4 & + & \\
\hline Mimozyganthus carinatus (Griseb.) Burkart & 1 & 3 & 1 & \\
\hline Prosopis flexuosa DC. & + & + & 1 & 1 \\
\hline Setaria cordobensis R.A.W. Herrm. & 1 & 1 & 1 & 1 \\
\hline Larrea divaricata Cav. & 4 & 2 & 3 & 2 \\
\hline Aspidosperma quebracho blanco Schltdl. & 1 & + & + & 2 \\
\hline Justicia squarrosa Griseb. & & & 2 & 4 \\
\hline Cordobia argentea (Griseb.) Nied. & 1 & & 2 & 3 \\
\hline Acacia gilliesii Steud. & & + & 3 & 2 \\
\hline Bromelia urbaniana (Mez) L.B. Sm. & & & 1 & 2 \\
\hline Celtis ehrenbergiana (Klotzsch) Liebm. & + & & + & 1 \\
\hline Lycium elongatum Miers & & & + & \\
\hline Condalia microphylla Cav. & 1 & & + & \\
\hline Trichloris crinita (Lag.) Parodi & 1 & 1 & + & \\
\hline Gouinia paraguayensis (Kuntze) Parodi & 1 & + & + & \\
\hline Geoffroea decorticans (Gillies ex Hook. \& Arn.) Burkart & 1 & & + & \\
\hline Amphilophium cynanchoides (DC.) L.G. Lohmann & 1 & & & \\
\hline Cercidium praecox (Ruiz \& Pav. ex Hook.) Harms & + & & + & \\
\hline Tillandsia duratii var. duratii Vis. & & + & 1 & 1 \\
\hline
\end{tabular}

$H$ : shannon-weaver biodiversity index; $L$ : lyapunov coefficient; $\mu$ : statistical mean; $\sigma$ : standard deviation, all based on the total number of surveyed sites. Bold data indicate the representative species of the community. ${ }^{*}$ Different letters indicate significant differences between states $(P<0.05$; LSD Fisher).

gradient is less intense in the first than in the second. These changes in the vegetation are due to anthropic effects (logging, overgrazing) or natural catastrophic events (fire) and represent secondary successions.

A high magnitude disturbance means high consumption of stored exergy, which is maximal in the mature state and is represented as high density biomass (wood) in the communities of $A$. quebracho blanco, being $L$ minimal.

The communities of $A$. gilliesii represent vegetation states into the Arid Chaco but also constitute transitions between this subregion and the Sierra Chaco subregion. This is why they present high values (though without statistical differences with other states) of $H$. In this case, changes in the dominant vegetation are not due to anthropic effects but to soil changes (Lithic Torriorthents) and climate, generating less favorable conditions for communities of A. quebracho blanco due to lesser soil profile development, water accumulation, and mean temperatures. According to Clements [2] this transition occurs by natural changes, being part of a primary succession.

Holling [26] criticizes the Clementsian model by considering that the species entering in a succession is largely stochastic, that the arrival of the species does not follow a defined order, but these are already in the site (e.g., seed bank), and some disturbing can lead the system to a quasistable state, different than the existing. Then, we will see that some ecological characteristics particular of this subregion contradict these assertions.

According to some observations made in other sites of the subregion [27-30], we can assert that when the succession develops over azonal soils it reaches in most cases to the same vegetation state (communities of A. quebracho blanco), although it may cross through different paths depending of the adjacent ecosystems and the dominant vegetation states. In this study, the natural succession would be the $L$. divaricata-M. carinatus-A. gilliesii-A. quebracho blanco way, 
although a regression does not necessarily follow the inverse way, but depends on the level of disturbance (selective logging of firewood).

The exceptions observed in this subregion are the successions facilitated by cattle, which generally end in dense Prosopis flexuosa woodlands by seed dispersion effect. However, cattle raising is a relatively recent human activity in this subregion (at least related to the succession scale), so it is possible that finally this woodlands can be replaced by $A$. quebracho blanco woodlands, due to their higher capacity to compete for light in their adult stage [31].

Allelopathic effects of $L$. divaricata restrict the random installation of species, though would act as nurse for species such as $M$. carinatus and $A$. gilliesii, adapted to dense canopies; however, they are more exigent in water and nutriments [32]. A. quebracho blanco would also develop under the influence of L. divaricata, M. carinatus [33], and A. gilliesii, according to the observed in Figure 3. However, in Figure 3 it can also be observed that A. quebracho blanco frequency increases after a drastic decrease of $M$. carinatus frequency, phenomenon that should be studied in better detail.

Climatic and topographic conditions would restrict the development of invasive allochthonous species. In fact, it is rare to find exotic species outside the influence of water sources.

Lyapunov coefficients adequately define the state of each site. When $L$ decreases in time, it is expected that the system moves towards a quasistationary state (communities of $A$. quebracho blanco); otherwise, the equilibrium is unstable and becomes less resilient [1]. Environmental degradation may produce a regression in secondary successions through deforestation, overgrazing, and fire processes, contributing to desertification.

Presumably, vegetation states with higher species abundance and frequency have the capacity to store higher amounts of exergy as biomass and as information $[10,15]$.

With respect to species diversity, this has a clear and significant effect over disturbance resistance, but equivocal in the recovery rate [34]. The Biodiversity Index can be a good indicator for primary successions but fails modeling secondary successions. Due to this, biodiversity indicators would not be sufficient to define the systems stability, neither would be satisfactory for the evaluation of the system stability. Lyapunov coefficients may be more precise successions indicators than the diversity indexes.

\section{Conclusions}

In the Arid Chaco subregion it is possible to identify a secondary succession conformed by vegetation states dominated by populations of $L$. divaricata, $M$. carinatus, A. gilliesii, and A. quebracho blanco.

Biological diversity indexes can be useful for primary successions but fail to predict the behavior of secondary successions. Exergy values could be used for the evaluation of secondary successions produced by environmental degradation in similar areas of the ecoregion and could be applied in similar ecosystems worldwide.

The distance between a representative "climax" state of the subregion, with respect to a reference state, permits estimation of the deterioration degree and the amount of exergy needed to reach a desired state (not necessarily the "climax"). The exergy can be estimated through Lyapunov coefficients as a measure of stability of the system. The exergetic calculus permits the obtaining of comparable values with other successional states in the subregion, though with the values in other ecosystems.

The identification of the vegetation states and transitions conducts to a better knowledge of the ecosystem's dynamic and enables to establish homogeneous areas for the construction of management guidelines for each one.

\section{References}

[1] M. S. Karlin, O. A. Bachmeier, A. Dalmasso, J. M. Sayago, and R. Sereno, "Environmental dynamics in salinas grandes, Catamarca, Argentina," Arid Land Research and Management, vol. 25, no. 4, pp. 328-350, 2011.

[2] F. E. Clements, Plant Succession: An Analysis of the Development of Vegetation, Carnegie Institute of Washington, USA, 1916.

[3] H. A. Gleason, "The Structure and development of the plant association," Bulletin of Torrey Botanical Club, vol. 44, no. 10, pp. 463-481, 1917.

[4] A. G. Tansley, "The use and abuse of vegetational concepts and terms," Ecology, vol. 16, no. 3, pp. 284-307, 1935.

[5] J. Terradas, Ecología de la Vegetación, Omega, Barcelona, Spain, 2001.

[6] M. Westoby, B. Walker, and I. Noy-Meir, "Opportunistic management for rangelands not at equilibrium," Journal of Range Management, vol. 42, no. 4, pp. 266-274, 1989.

[7] C. J. Yates and R. J. Hobbs, "Woodland restoration in the Western Australian wheatbelt: a conceptual framework using a state and transition model," Restoration Ecology, vol. 5, no. 1, pp. 28-35, 1997.

[8] P. G. Spooner and K. G. Allcock, "Using a state-and-transition approach to manage endangered Eucalyptus albens (White Box) woodlands," Environmental Management, vol. 38, no. 5, pp. 771783, 2006.

[9] L. Rumpff, D. H. Duncan, P. A. Vesk, D. A. Keith, and B. A. Wintle, "State-and-transition modelling for Adaptive Management of native woodlands," Biological Conservation, vol. 144, no. 4, pp. 1244-1235, 2011.

[10] S. E. Jørgensen and Y. M. Svirezhev, Towards A Thermodynamic Theory for Ecological Systems, Elsevier, Amsterdam, The Netherlands, 2004.

[11] B. C. Patten, "An introduction to the cybernetics of the ecosystem: the trophic-dynamic aspect," Ecology, vol. 40, no. 2, pp. 221-231, 1959.

[12] I. Prigogine and I. Stengers, La Nueva Alianza. Metamorfosis de La Ciencia, Alianza Universidad, Madrid, Spain, 2nd edition, 2004.

[13] E. D. Schneider and J. J. Kay, "Order from disorder: the thermodynamics of complexity in biology," in What Is Life: The Next Fifty Years. Reflections on the Future of Biology, M. P. Murphy and L. A. J. O’Neill, Eds., pp. 161-172, Cambridge University Press, Cambridge, UK, 1995. 
[14] G. M. Souza, R. V. Ribeiro, M. G. Santos, H. L. Ribeiro, and R. F. Oliveira, "Functional groups of forest succession as dissipative structures: an applied study," Brazilian Journal of Biology, vol. 64, no. 3B, pp. 707-718, 2004.

[15] J. Molozzia, F. Salas, M. Callistoa, and J. C. Marques, “Thermodynamic oriented ecological indicators: application of EcoExergy and specific Eco-Exergy in capturing environmental changes between disturbed and non-disturbed tropical reservoirs," Ecological Indicators, vol. 24, pp. 543-551, 2013.

[16] E. Schrödinger, ¿Qué es la vida? Tusquets Editores, Barcelona, Spain, 1983.

[17] M. L. Carranza, M. R. Cabido, A. Acosta, and S. A. Páez, "Las comunidades vegetales del Parque Natural Chancaní, Provincia de Córdoba," Lilloa, vol. 38, pp. 75-92, 1992.

[18] R. G. Capitanelli, “Clima," in Geografía Fsica de la Provincia de Córdoba, J. B. Vázquez, R. A. Miatello, and M. E. Roqué, Eds., pp. 45-138, Editorial Boldt, Córdoba, Argentina, 1979.

[19] D. Mueller-Dombois and H. Ellenberg, in Aims \& Methods of Vegetation Ecology, John Wiley \& Sons, US, 1974.

[20] J. Braun-Blanquet, Fitosociología. Bases para el estudio de las comunidades vegetales, Blume, Madrid, Spain, 1979.

[21] D. A. Wikum and G. F. Shanholtzer, "Application of the BraunBlanquet cover-abundance scale for vegetation analysis in land development studies," Environmental Management, vol. 2, no. 4, pp. 323-329, 1978.

[22] J. Di Rienzo, F. Casanoves, L. Gonzalez, M. Tablada, C. Robledo, and M. Balzarini, "Infostat," Facultad de Ciencias Agropecuarias, Universidad Nacional de Córdoba. Statistical software, 2007.

[23] J. Justus, "Ecological and Lyapunov stability," Philosophy of Science, vol. 75, no. 4, pp. 421-436, 2008.

[24] E. E. Bonino and P. Araujo, "Structural differences between a primary and a secondary forest in the Argentine Dry Chaco and management implications," Forest Ecology and Management, vol. 206, no. 1-3, pp. 407-412, 2005.

[25] M. D. R. Iglesias, A. Barchuk, and M. P. Grilli, "Carbon storage, community structure and canopy cover: a comparison along a precipitation gradient," Forest Ecology and Management, vol. 265, pp. 218-229, 2012.

[26] C. S. Holling, "Cross-scale morphology, geometry, and dynamics of ecosystems," Ecological Monographs, vol. 62, no. 4, pp. 447-502, 1992.

[27] U. O. Karlin, M. Karlin, and E. J. Ruiz Posse, "Ambientes y vegetación," in Manejo Sustentable del Ecosistema Salinas Grandes, Chaco Árido, R. Coirini, M. Karlin, and G. Reati, Eds., pp. 91-118, Encuentro, Córdoba, Argentina, 2010.

[28] H. Calella and R. R. Corzo, El Chaco Árido de La Rioja. Vegetación y suelos. Pastizales naturales, Ediciones INTA, Buenos Aires, Argentina, 2006.

[29] D. L. Anderson, J. A. Del Águila, and A. E. Bernardón, "Las formaciones vegetales en la Provincia de San Luis," Revista de Investigaciones Agropecuarias, vol. VII, no. 3, pp. 153-183, 1970.

[30] J. Morello, "Provincia fitogeográfica del monte," Opera Lilloana, vol. 2, pp. 1-155, 1958.

[31] L. Catalán, Crecimiento leñoso de Prosopis flexuosa en una sucesión post-agrícola en el Chaco Árido: efectos y relaciones de distintos factores de proximidad [Ph.D. thesis], FCEFyN-UNC, Córdoba, Argentina, 2000.

[32] S. A. Páez and D. E. Marco, "Seedling habitat structure in dry Chaco forest (Argentina)," Journal of Arid Environments, vol. 46, no. 1, pp. 57-68, 2000.
[33] A. H. Barchuk, M. D. R. Iglesias, and M. N. Boetto, "Spatial association of Aspidosperma quebracho-blanco juveniles with shrubs and conspecific adults in the Arid Chaco, Argentina," Austral Ecology, vol. 33, no. 6, pp. 775-783, 2008.

[34] D. Tilman, "Biodiversity: population versus ecosystem stability," Ecology, vol. 77, no. 2, pp. 350-363, 1996. 

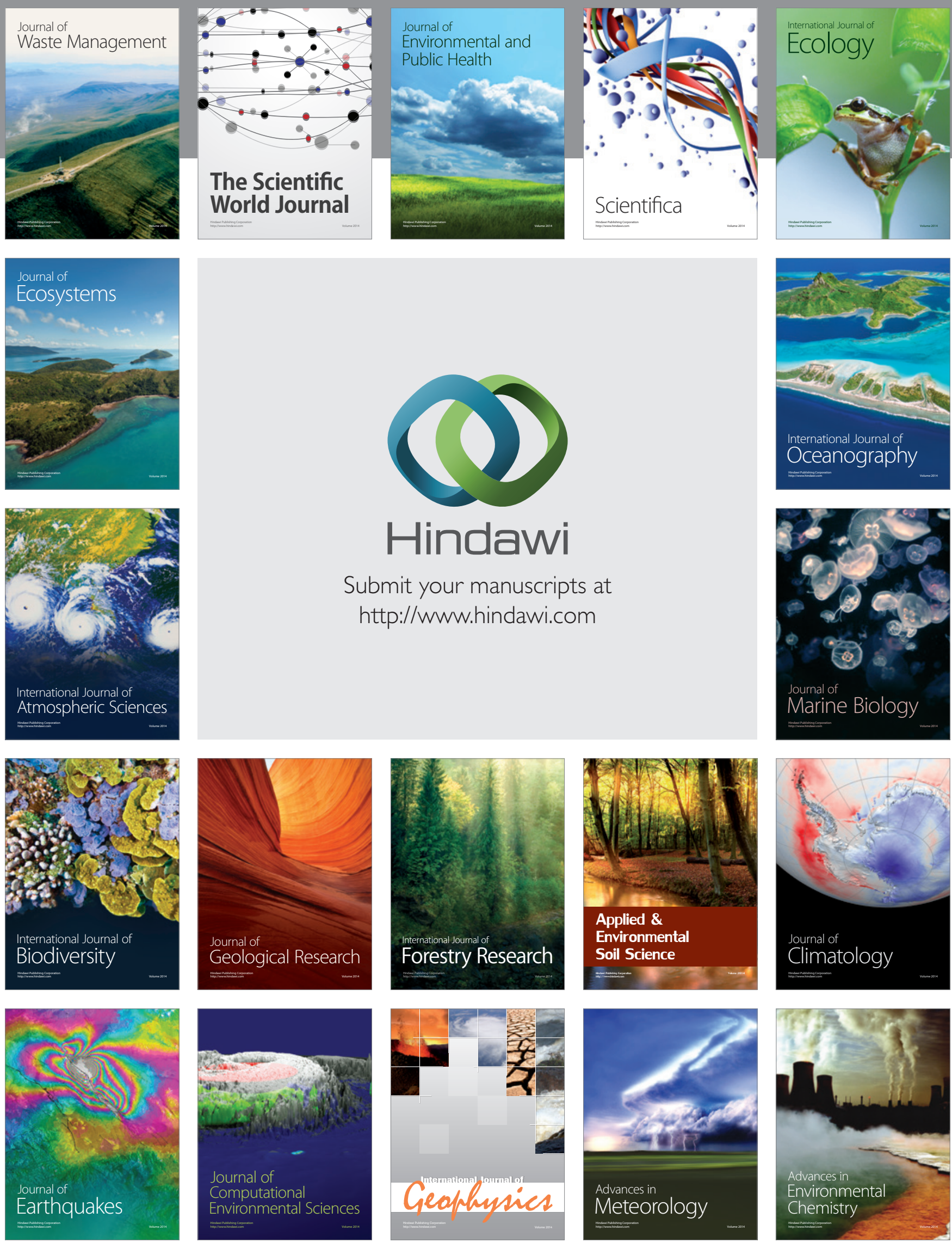